\title{
PLASMA RICO EM PLAQUETAS DE COELHOS: INTRODUÇÃO A UM MODELO ANIMAL EXPERIMENTAL
}

\section{Platelet-rich plasma in rabbits: introduction of one experimental animal model}

\author{
Marco Antonio de OLIVEIRA-FILHO, Luís Eduardo ALMEIDA, Joacir Antonio PEREIRA, \\ Paulo Afonso Nunes NASSIF, Nicolau Gregori CZECZKO, \\ Márcio Hiroaki KUME, Marília Barreto Gameiro SILVA
}

ABCDDV/620

Oliveira-Filho MA, Almeida LE, Pereira JA, Nassif PAN, Czeczko NG, Kume MH, Silva MBG. Plasma rico em plaquetas de coelhos: introdução a um modelo animal experimental. ABCD Arq Bras Cir Dig 2008;21(4):175-9

RESUMO - Racional - Muitas dúvidas ainda permanecem no que se refere às ações dos fatores de crescimento e do plasma rico em plaquetas sobre o mecanismo de reparação tissular. Há necessidade de serem esclarecidos pontos controversos ainda existentes. Objetivo - Obter o plasma rico em plaquetas em coelhos através de um método simplificado e ao mesmo tempo adequado, introduzindo um modelo experimental que possa ser utilizado em estudos posteriores. Métodos - Foram utilizados 25 coelhas da raça Nova Zelândia e sem doenças prévias. Quinze $\mathrm{mL}$ de sangue de cada animal foi coletado, sendo $10 \mathrm{~mL}$ submetidos à dupla centrifugação. Para comprovar a efetividade do método proposto realizou-se contagem mecânica do sangue, bem como do produto final. Resultado - Obteve-se uma concentração média de plaquetas no plasma rico em plaquetas $687 \%$ maior que a contagem inicial observada no sangue venoso periférico. Para as variáveis: contagem inicial de plaquetas, contagem de plaquetas no plasma rico em plaquetas e enriquecimento, foram obtidos os limites de $95 \%$ de confiança para suas médias, sendo que, no que se refere ao percentual de enriquecimento, existe $95 \%$ de chance de que o intervalo de (530-844) contenha a média real de enriquecimento de plaquetas. Conclusão - O método simplificado utilizado permite a obtenção de plasma rico em plaquetas adequado permitindo seu uso em estudos dos fatores de crescimento nos mecanismos de reparação tecidual.

DESCRITORES - Cicatrização de Feridas . Plaquetas. Plasma rico em plaquetas.

\section{INTRODUÇÃO}

Estudos in vitro e in vivo têm sido desenvolvidos com o objetivo de se conhecer melhor os efeitos dos diversos fatores de crescimento no mecanismo de reparo ${ }^{20,25,27,34}$. Resultados promissores já foram obtidos quando da utilização de fatores de crescimento em situações de reparo tecidua $^{14,15,16,17,21,22,23,26,30,33,38}$.

Sabe-se, atualmente, que as plaquetas, além de outras células de natureza mesenquimal, atuam como uma fonte de fatores de crescimento. Entre os fatores de crescimento encontrados nas plaquetas estão o PDGF $^{2,6,11,12,18,24,29,31,37}$, TGF $\beta^{2,6,11,12,18,24,29,31,37}$, VEGF ${ }^{11,24}$, IGF-I ${ }^{12,24,31}$, PDECG $^{24}$, $\mathrm{PDAF}^{24}, \mathrm{EGF}^{12}$ e ECGF ${ }^{12}$.

O conhecimento do fato de serem as plaquetas, comprovadamente, fonte de fatores de crescimento incentivou o estudo da ação de um concentrado de plaquetas no sentido de se aumentar o nível de fatores de crescimento local, o que, teoricamente, melhoraria o processo cicatricial.

Diversos autores passaram a propor a utilização do

Trabalho realizado no Instituto de Pesquisas Médicas do Hospital Universitário Evangélico de Curitiba/Faculdade Evangélica do Paraná, Curitiba, PR, Brasil.

Correspondência: Marco Antonio de Oliveira-Filho, e-mail oliveirafilho-ma@uol.com.br plasma rico em plaquetas (PRP), principalmente em associação com enxertos ósseos ${ }^{2,11,14,19,29,31,36,37}$, embora ele venha sendo utilizado, também, com o objetivo de melhorar o reparo de tecidos moles ${ }^{24}$.

Ainda não há consenso no que se refere à concentração de plaquetas ideal ou, até mesmo, qual seria a concentração mínima de plaquetas que otimizaria o processo de reparação. Concentração de plaquetas pelo menos quatro vezes maior que a verificada no sangue venoso periférico parece ser parâmetro confiável para que o PRP possa ser considerado como adequado ${ }^{18}$. Alguns estudos indicam que um PRP altamente concentrado seria, até mesmo, prejudicial ao mecanismo de reparação $0^{4,35}$.

Equipamentos foram desenvolvidos com o objetivo de produzi-lo de forma automática ou semi-automática, porém muitas destas máquinas não têm se mostrado eficazes em produzir concentração adequada e que permitam liberação posterior de fatores de crescimento em níveis terapêuticos ${ }^{19}$.

Ainda está longe de haver unanimidade a respeito da efetividade do concentrado de plaquetas no sentido de melhora do reparo tecidual.Trabalhos mostram resultados positivos $^{3,7,9,11,13,18}$, e também resultados pobres ${ }^{1,8,11}$ quando da utilização desse concentrado. O que se questiona com relação aos artigos que mostram poucos benefícios dele, 
é se o material utilizado é de fato um concentrado de plaquetas adequado, se as plaquetas não foram danificadas durante o processo de concentração, se as plaquetas foram realmente ativadas e se os resultados foram estatisticamente válidos ${ }^{19}$.

Alguns estudos sugeriram que o plasma seria prejudicial à cicatrização, estabelecendo a hipótese de que um concentrado de plaquetas sem plasma poderia ser mais interessante no sentido de otimizar o processo reparador tecidual ${ }^{5}$.

Assim, este estudo foi realizado com a finalidade de se obter o PRP através de protocolo simplificado, produzindo em modelo experimental em coelhas um PRP adequado, permitindo que este modelo animal possa ser utilizado em estudos posteriores no que se refere à ação dos fatores de crescimento.

\section{MÉTODOS}

O estudo foi realizado no Instituto de Pesquisas Médicas (IPEM) do Hospital Universitário Evangélico de Curitiba. A partir de coelhas foi obtido o sangue para produzir o PRP através de método de centrifugação. As variáveis registradas no experimento foram: contagem inicial de plaquetas e contagem de plaquetas do PRP. O valor do enriquecimento foi obtido dividindo-se o valor da contagem de plaquetas do PRP pelo valor da contagem inicial de plaquetas, diminuído em uma unidade e multiplicado por $100 \%$. Desta forma, o enriquecimento foi considerado como sendo o ganho percentual de plaquetas a partir da contagem inicial.

Utilizaram-se 25 coelhas brancas adultas, da raça Nova Zelândia, sem doenças prévias, com idade variando entre 350 e 370 dias e com peso entre 2750 e 4600 gramas na ocasião do experimento. Os animais foram provenientes do biotério do IPEM. Foram respeitados os princípios éticos na experimentação animal, preconizados pelo Colégio Brasileiro de Experimentação Animal e o protocolo deste estudo foi aprovado pelo Comitê de Ética em Pesquisa da Sociedade Evangélica Beneficente de Curitiba.

Os animais foram anestesiados através da administração de solução estéril de cloridrato de ketamina a 5\% (Vetanar$\mathrm{col}^{\circledR}$ König S.A., Avellaneda, Argentina) via intramuscular na proporção de $0,5 \mathrm{~mL} / \mathrm{Kg}$. Considerou-se a anestesia como efetiva quando o animal apresentou-se imóvel ao manuseio.

Foi realizado procedimento de tricotomia em uma das orelhas de cada animal com a utilização de lâmina de aço inoxidável.

Para obtenção da amostra de sangue venoso foi puncionada a veia que se mostrou clinicamente mais favorável à coleta na orelha, sendo utilizado um scalp número 21 . Após a punção conectou-se uma seringa de $15 \mathrm{~mL}$ contendo $1,5 \mathrm{~mL}$ do anticoagulante citrato (Bioclin Química Básica Ltda, Belo Horizonte, Brasil), permitindo, desta maneira, a coleta do sangue.

Obteve-se aproximadamente $15 \mathrm{~mL}$ de sangue de cada coelha, sendo $10 \mathrm{~mL}$ transferido para um tubo com medidas de 16X100 mm (Vacuotainer ${ }^{\circledR}$, BD, Curitiba-Brasil) e aproximadamente $4 \mathrm{~mL}$ transferido para outro tubo com medidas de 12 X75mm (Vacuotainer ${ }^{\mathbb{R}}, \mathrm{BD}$, Curitiba-Brasil).

Realizou-se a contagem automática de plaquetas do material obtido e armazenado nos tubos de $12 \mathrm{X} 75 \mathrm{~mm}$.

Para o preparo do PRP foi utilizada uma centrífuga comum de laboratório (Excelsa II Baby 206 R, Fanem, São Paulo, Brasil). Primeiramente os tubos foram centrifugados a 200 gravidades durante 20 minutos, permitindo a formação de dois níveis distintos, com a separação da fração de plasma na parte superior do tubo (coloração levemente amarelada) da fração de células sanguíneas vermelhas (coloração vermelha), que permanece no fundo do tubo (Figura 1).

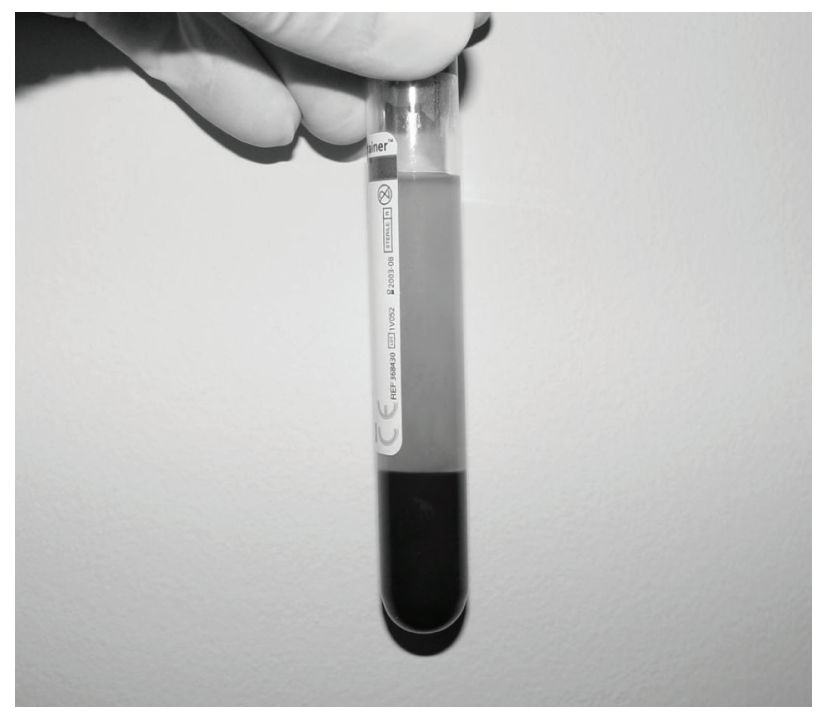

FIGURA 1 - Aspecto após a primeira centrifugação, onde se observam dois níveis distintos: um superior de coloração amarelada (cor mais clara) e outro inferior com coloração vermelha (cor mais densa)

Toda a fração correspondente ao plasma e o $1 \mathrm{~mL}$ mais superior da fração vermelha foram transferidos para um outro tubo e submetidos à segunda centrifugação a 400 gravidades durante 10 minutos. Após, formaram-se dois níveis distintos: um superior com coloração levemente amarelada e um nível inferior avermelhado (Figura 2).

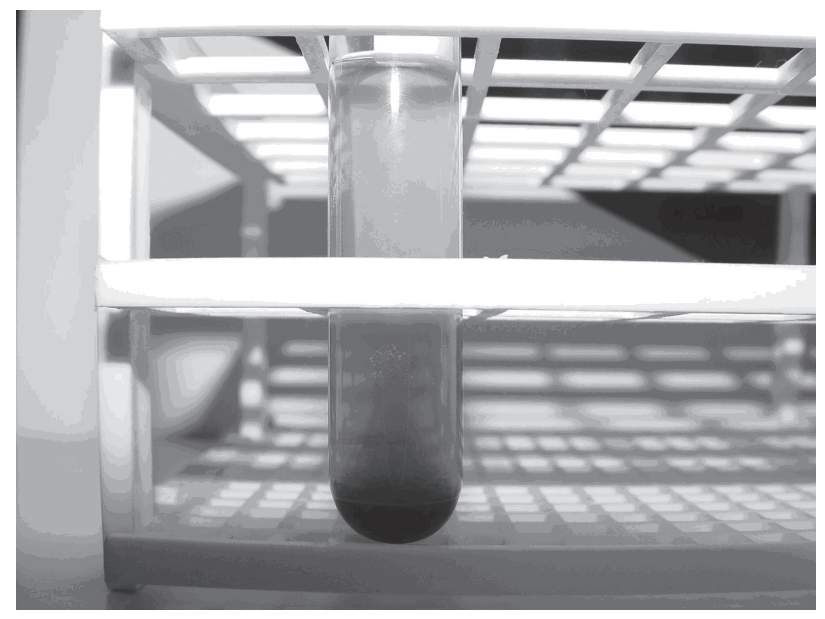

FIGURA 2 - Aspecto após a segunda centrifugação com destaque para o nível inferior avermelhado (cor mais densa) 
Removeu-se o nível superior, com exceção de sua parte mais inferior e apenas em quantidade suficiente para que, somado com a fração vermelha inferior, o total completasse $1 \mathrm{~mL}$ (Figura 3). Após homogeneização obteve-se $1 \mathrm{~mL}$ do produto final a partir de $10 \mathrm{ml}$ de sangue (Figura 4).

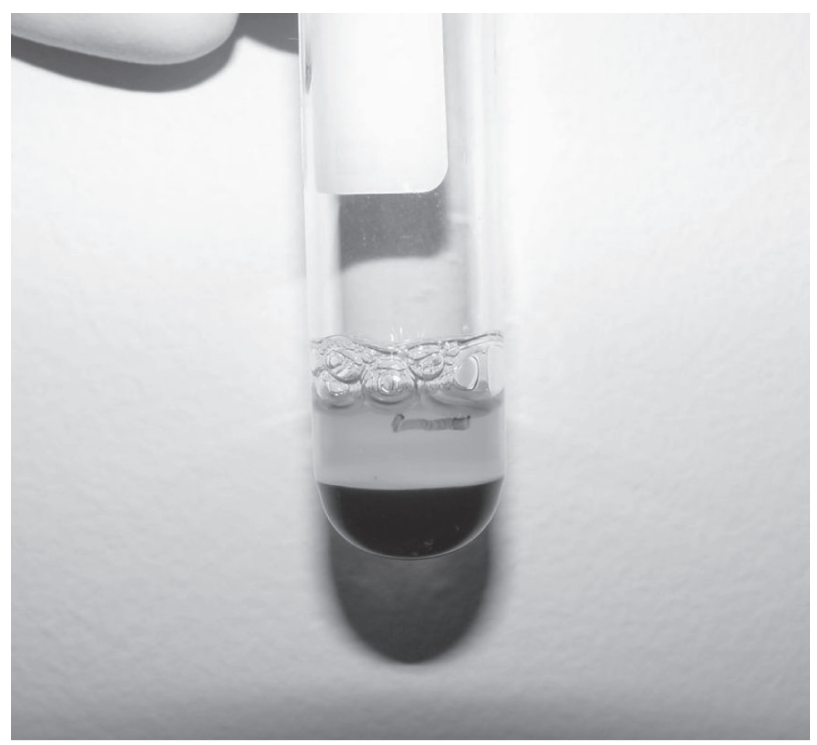

FIGURA 3 - Remoção do nível superior em sua totalidade permanecendo apenas volume tal que somado ao nível inferior resultasse em $1 \mathrm{~mL}$

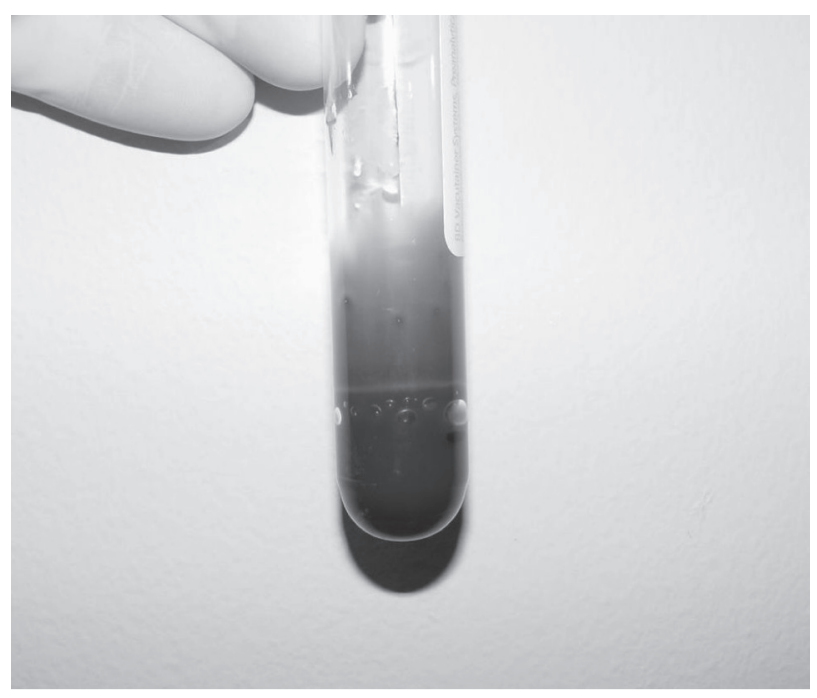

FIGURA 4 - Aspecto após a homogeneização

Realizou-se contagem mecânica do número de plaquetas do PRP da mesma maneira utilizada para a contagem inicial de plaquetas. Foram avaliadas as variáveis: contagem inicial de plaquetas, contagem de plaquetas do PRP e percentual de enriquecimento.

Para todas as variáveis consideradas no estudo foram apresentados valores de mediana, valor mínimo, valor máximo, média e desvio-padrão. Para as variáveis contagem inicial de plaquetas, contagem de plaquetas do PRP e enriquecimento, foram construídos intervalos de $95 \%$ para as médias. Para investigar a associação entre a contagem inicial de plaquetas e contagem de plaquetas do PRP estimou-se o coeficiente de correlação de Spearman e testou-se a hipótese nula de ausência de correlação entre as variáveis, versus a hipótese alternativa da correlação entre elas. O nível de significância considerado foi de $5 \%$.

\section{RESULTADOS}

Para todas as variáveis obteve-se os valores de mediana, valor mínimo, valor máximo, média e desvio-padrão. A Tabela 1 apresenta estes resultados que permitem afirmar que existe $95 \%$ de chance de que o intervalo de (257.797;345.003) contém a média real da contagem inicial de plaquetas. Já, este intervalo para a contagem de plaquetas no PRP é de (1.775.794;3.053.646) e, em relação ao percentual de enriquecimento, o intervalo de $95 \%$ de confiança para a média é de 530 a $844 \%$.

TABELA 1 - Mediana, valor mínimo, valor máximo, média e desvio-padrão das variáveis

\begin{tabular}{lcccc}
\hline Variável & Mediana & $\begin{array}{c}\text { Valor } \\
\text { mínimo }\end{array}$ & $\begin{array}{c}\text { Valor } \\
\text { máximo }\end{array}$ & $\begin{array}{c}\text { Média } \pm \text { Des- } \\
\text { vio Padrão }\end{array}$ \\
\hline Contagem inicial deplaquetas & 309.000 & 103.000 & 500.000 & $\begin{array}{c}301.400 \pm \\
105.632\end{array}$ \\
Contagem deplaquetas doPRP & 2.150 .000 & 612.000 & 6.880 .000 & $\begin{array}{c}2.414 .720 \pm \\
1.547 .862 \\
\text { Enriquecimento (\%) }\end{array}$ \\
\hline
\end{tabular}

No que se refere à associação entre contagem inicial de plaquetas e contagem de plaquetas no PRP o valor do coeficiente de correlação estimado foi de 0,6785 e o resultado do teste indicou a rejeição da hipótese nula no nível de significância de $5 \%(P=0,0002)$. Desta forma pode-se dizer que há associação significativa entre a contagem inicial de plaquetas e a contagem de plaquetas do PRP obtido.

\section{DISCUSSÃO}

Nos dias atuais muito ainda permanece incerto com relação à ação dos fatores de crescimento e do PRP no mecanismo de reparo. Estas incertezas justificam a introdução de um modelo animal experimental que permita a obtenção de um PRP adequado, permitindo, consequentemente, que este modelo possa ser utilizado em estudos posteriores.

Sabe-se que as plaquetas são fonte de diversos fatores de crescimento. O PDGF e o TGF- $\beta$ parecem ser os fatores de crescimento principais do PRP, já que quando são mencionados os fatores de crescimento encontrados nas plaquetas, aqueles são sempre citados $2,6,11,12,18,29,31,37$.

Um parâmetro através do qual pode-se verificar o grau de importância que está sendo dado ao PRP são as suas principais aplicações clínicas atuais em odontologia e medicina, como: utilização em enxertos ósseos após procedimentos ablativos na região maxilofacial ${ }^{18,37}$; utilização em enxertos ósseos no processo alveolar; atuando como coadjuvante nos procedimentos de implantodontia ${ }^{2,11,31,37}$; em procedimentos de sinus lift ${ }^{11,29,36}$; para compactação e facilitação no manuseio de enxertos particulados ${ }^{13,14,18,31,37}$, 
em procedimentos de enxertia de tecidos moles em região periodontal ${ }^{24}$, vitrectomia ${ }^{10}$ e ritidectomia ${ }^{28}$, entre outros.

Na literatura verifica-se que diversas técnicas são empregadas com o objetivo de produzir o PRP. Existem relatos da produção dele a partir de uma unidade de sangue total (aproximadamente $450 \mathrm{~mL}$ ), com devolução à circulação da fração de células sanguíneas vermelhas e plasma pobre em plaquetas para minimizar a perda sanguínea ${ }^{18,29,36}$. Muitos dos procedimentos de enxertia óssea, principalmente nas áreas de cirurgia maxilofacial e implantodontia, necessitam de quantidade de PRP muito menor do que a obtida a partir de uma unidade de sangue ${ }^{14}$.

Este estudo produziu $1 \mathrm{~mL}$ de PRP a partir de $10 \mathrm{~mL}$ de sangue, lembrando sempre que, caso o procedimento necessite de quantidade maior ou menor de PRP, o sangue pode ser coletado sempre de acordo com esta necessidade.

Diversos aparelhos tem sido lançados no mercado e que têm como objetivo a produção de PRP de forma automática ou semi-automática, empregando técnica de centrifugação. Para Marx $^{19}$ é importante que se saiba se determinado aparelho que visa a produção de PRP é realmente capaz de concentrar plaquetas e, o que é mais importante, se é capaz de liberar fatores de crescimento em níveis terapêuticos.

O que se observa atualmente é que diversos protocolos estão sendo propostos visando obter um PRP adequado a partir de quantidades pequenas de sangue, que utilizem centrífugas comuns de laboratório, e que permitem a produção de quantidades de PRP suficientes para a maioria dos procedimentos em cirurgia oral e maxilofacial, até mesmo em consultório ${ }^{2,8,13}$.

A produção do PRP nas 25 coelhas estudados seguiu esta linha de pensamento já que utilizou uma centrífuga de laboratório e obteve PRP a partir de quantidades pequenas de sangue.

O protocolo para obtenção do concentrado de plaquetas empregado neste trabalho segue basicamente o proposto por Sonnleitner et al. ${ }^{32}$, com algumas alterações. Segundo este protocolo, o PRP é obtido através de uma técnica onde o sangue periférico do paciente é obtido e transferido para tubos de $6 \mathrm{~mL}$ com citrato. Os tubos são centrifugados por 20 minutos a $160 \mathrm{~g}$. Esta centrifugação resulta em fração inferior vermelha opaca e outra superior ligeiramente amarelada e turva. Verificaram após esta primeira centrifugação, começando no limite superior e em intervalos de $250 \mu 1$, que a concentração de plaquetas varia de 22.000 a 24.000 plaquetas. A partir do ponto $6 \mathrm{~mm}$ abaixo do limite superior da fração vermelha a contagem aumenta de 37.000 a 45.000 por $250 \mu 1$. Dentro dos primeiros $6 \mathrm{~mm}$ da fração vermelha a contagem de plaquetas aumenta para 90.000 , e $9 \mathrm{~mm}$ dentro da fração vermelha cai para 53.000. Como a concentração máxima de plaquetas está 6 a $8 \mathrm{~mm}$ abaixo da linha de divisão entre as duas fases, dentro da fração vermelha, a totalidade acima deste ponto é pipetada e colocada em um tubo para que seja centrifugada novamente por 15 minutos a 400g. Após esta segunda centrifugação obtiveram valores entre 8.000 e 11.000 plaquetas no nível superior amarelado, verificando no nível inferior valores que excedem o limite de 2.000.000 plaquetas. Dentro da literatura este protocolo pareceu o mais efetivo no sentido de se conseguir altas concentrações de plaquetas, o que foi confirmado com os resultados obtidos.

Permanece ainda muito incerto o conceito de PRP adequado. Leva-se em consideração, primeiramente, a sua concentração de plaquetas. Através do protocolo proposto neste trabalho obtive-se $1 \mathrm{~mL}$ de PRP a partir de $10 \mathrm{~mL}$ de sangue, com concentração média de $687 \%$ acima dos números verificados no sangue venoso periférico. Marx ${ }^{19}$, discutindo o artigo de Landsberg et al. ${ }^{14}$ afirmou que considera que a concentração de plaquetas do PRP deve ser pelo menos quatro vezes maior que a concentração de plaquetas basal. Alguns estudos procuraram analisar a efetividade do PRP no sentido de potencializar o reparo, relacionando os resultados obtidos com as várias concentrações de plaquetas empregadas. Resultados tem mostrado que a efetividade do PRP pode seguir padrão concentração-dependente, ou seja, concentrações muito altas teriam efeito prejudicia ${ }^{35}$. Este modelo poderia ser empregado no sentido de se verificar as concentrações ideais, já que concentrações menores poderiam ser obtidas bastando adicionar quantidades maiores de plasma no produto final, após a segunda centrifugação.

Outro fator a ser considerado é que a centrifugação do sangue deverá ser realizada sem o emprego de forças excessivas, de modo a não danificar as plaquetas irreversivelmente. Este modelo procurou evitar o emprego de forças excessivas de centrifugação.

Importante também no PRP é que este seja produzido em volume adequado para o procedimento proposto. Após a segunda centrifugação este estudo obteve nível inferior avermelhado e altamente concentrado em plaquetas. Para completar o volume de $1 \mathrm{~mL}$ foi acrescentado a quantidade suficiente do nível superior que, embora seja menos concentrado, forneceu após homogeneização volume adequado. Caso deseja-se concentração de plaquetas ainda maior, utilizar-se-ia apenas o nível inferior avermelhado, praticamente isento de plasma, porém com o inconveniente de volume menor no produto final. Como já foi dito, ainda permanece incerto se este eventual aumento de concentração seria benéfico no sentido de melhorar o reparo tecidual.

Alguns estudos têm sugerido que o plasma seria prejudicial ao reparo tecidual, ou seja, seria mais interessante a utilização de concentrado de plaquetas sem plasma ${ }^{5}$. Caso seja utilizada apenas a fração vermelha inferior, fração esta obtida após a segunda centrifugação, ter-se-ia concentrado de plaquetas sem plasma. Ele poderia ser misturado com cola de fibrina disponível comercialmente, permitindo o estudo dos efeitos do concentrado de plaquetas isento de plasma.

\section{CONCLUSÃO}

O método simplificado para a produção do plasma rico em plaquetas utilizado neste estudo, além de dispensar a utilização de equipamentos de alto custo e sofisticados, permite a obtenção de produto adequado ao uso em estudos dos fatores de crescimento nos mecanismos de reparação tecidual. 
Oliveira-Filho MA, Almeida LE, Pereira JA, Nassif PAN, Czeczko NG, Kume MH, Silva MBG. Platelet-rich plasma in rabbits: introduction of one experimental animal model. ABCD Arq Bras Cir Dig 2008;21(4):175-9

ABSTRACT - Background - Multiple uncertainties still exist about the action of the growth factors and the platelet-rich plasma on the mechanism of repair. Aim - To obtain the platelet-rich plasma in rabbits through a simplified and suitable method, creating an experimental model. Methods -Twenty-five female New Zealand rabbits without previous diseases were used. Fifteen $\mathrm{mL}$ of blood of each rabbit was collected and $10 \mathrm{~mL}$ of the collected blood were twice centrifugated. To check the effectiveness of the proposed method mechanical counting of the blood and of the final product were performed. Results - The mean platelet concentration was $687 \%$ higher than the initial peripheral blood counting. Mean initial platelet counting, platelet-rich plasma platelet counting and enriched were obtained with $95 \% \mathrm{CI}$ and in terms of enrichment percentage there is a chance that the interval 530 to 844 be the real mean platelet enrichment. Conclusion - This simplified method permits to get an effective platelet-rich plasma to be used in trials about growth factors in mechanisms of tissue repair.

HEADINGS - Wound healing. Blood platelets. Platelet-rich plasma.

\section{REFERÊNCIAS}

1. Aghaloo TL, Moy PK, Freymiller EG. Investigation of platelet-rich plasma in rabbit cranial defects: A pilot study. J Oral Maxillofac Surg. 2002 Oct;60(10):1176-81.

2. Anitua E. Plasma rich in growth factors: preliminary results of use in the preparation of future sites for implants. Int J Oral Maxillofac Implants. 1999 Jul-Aug; 14(4):529-35.

3. Camargo PM, Lekovic V, Weinlaender M, Vasilic N, Madzarevic M, Kenney EB. Platelet-rich plasma and bovine porous bone mineral combined with guided tissue regeneration in the treatment of intrabony defects in humans. $\mathrm{J}$ Periodontal Res. 2002 Aug;37(4):300-6.

4. Cho MI, Lin WL, Genco RJ. Platelet-derived growth factor-modulated guided tissue regenerative therapy. J Periodontol. 1995; 66(6): 522-30.

5. Choi BH, Zhu SJ, Kim BY, Huh JY, Lee SH, Jung JH. Effect of platelet-rich plasma (PRP) concentration on the viability and proliferation of alveolar bone cells: an in vitro study. Int J Oral Maxillofac Surg. 2005 Jun;34(4):420-4.

6. Cromack DT, Porras-Reyes B, Mustoe TA. Current concepts in wound healing: growth factor and macrophage interaction. J Trauma. $1990 \mathrm{Dec} ; 30$ (12 Suppl):S129-33.

7. Elgazzar RF, Mutabagani MA, Abdelaal SE, Sadakah AA. Platelet rich plasma may enhance peripheral nerve regeneration after cyanoacrylate reanastomosis: a controlled blind study on rats. Int J Oral Maxillofac Surg. 2008 Aug;37(8):74855.

8. Froum SJ, Wallace SS, Tarnow DP, Cho SC. Effect of platelet-rich plasma on bone growth and osseointegration in human maxillary sinus grafts: three bilateral case reports. Int J Periodontics Restorative Dent. 2002 Feb;22(1):4553.

9. Garg AK. The use of platelet-rich plasma to enhance the success of bone grafts around dental implants. Dent Implantol Update. 2000 Mar;11(3):17-21.

10. Gehring S, Hoerauf H, Laqua H, Kirchner H, Klüter H. Preparation of autologous platelets for the ophthalmologic treatment of macular holes. Transfusion. 1999 Feb;39(2):144-8.

11. Kassolis JD, Rosen PS, Reynolds MA. Alveolar ridge and sinus augmentation utilizing platelet-rich plasma in combination with freeze-dried bone allograft: case series. J Periodontol. 2000 Oct;71(10):1654-61.

12. Kiuru J, Viinikka L, Myllylä G, Pesonen K, Perheentupa J. Cytoskeletondependent release of human platelet epidermal growth factor. Life Sci. 1991;49(26):1997-2003.

13. Kroese-Deutman HC, Vehof JW, Spauwen PH, Stoelinga PJ, Jansen JA. Orthotopic bone formation in titanium fiber mesh loaded with platelet-rich plasma and placed in segmental defects. Int J Oral Maxillofac Surg. 2008 Jun;37(6):542-9.

14. Landesberg R, Roy M, Glickman RS. Quantification of growth factor levels using a simplified method of platelet-rich plasma gel preparation. J Oral Maxillofac Surg. 2000 Mar;58(3):297-300.

15. Lynch SE, Buser D, Hernandez RA, Weber HP, Stich H, Fox CH, Williams RC. Effects of the platelet-derived growth factor/insulin-like growth factor-I combination on bone regeneration around titanium dental implants. Results of a pilot study in beagle dogs. J Periodontol. 1991 Nov;62(11):710-6.

16. Lynch SE, Nixon JC, Colvin RB, Antoniades HN. Role of platelet-derived growth factor in wound healing: synergistic effects with other growth factors. Proc Natl Acad Sci U S A. 1987 Nov;84(21):7696-700.

17. Lynch SE, Williams RC, Polson AM, Howell TH, Reddy MS, Zappa UE, Antoniades HN. A combination of platelet-derived and insulin-like growth factors enhances periodontal regeneration. J Clin Periodontol. 1989 Sep;16(8):545-8.

18. Marx RE, Carlson ER, Eichstaedt RM, Schimmele SR, Strauss JE, Georgeff KR. Platelet-rich plasma: Growth factor enhancement for bone grafts. Oral Surg Oral Med Oral Pathol Oral Radiol Endod. 1998 Jun;85(6):638-46.

19. Marx RE. Platelet-rich plasma: evidence to support its use. J Oral Maxillofac Surg. 2004 Apr;62(4):489-96.

20. Mohan S, Baylink DJ. Bone growth factors. Clin Orthop Relat Res. 1991 Feb;(263):30-48.

21. Mustoe TA, Pierce GF, Morishima C, Deuel TF. Growth factor-induced acceleration of tissue repair through direct and inductive activities in a rabbit dermal ulcer model. J Clin Invest. 1991 Feb;87(2):694-703.
22. Nash TJ, Howlett CR, Martin C, Steele J, Johnson KA, Hicklin DJ. Effect of platelet-derived growth factor on tibial osteotomies in rabbits. Bone. 1994 Mar-Apr;15(2):203-8.

23. Park JB, Matsuura M, Han KY, Norderyd O, Lin WL, Genco RJ, Cho MI. Periodontal regeneration in class III furcation defects of beagle dogs using guided tissue regenerative therapy with platelet-derived growth factor. J Periodontol. 1995 Jun;66(6):462-77.

24. Petrungaro PS. Using platelet-rich plasma to accelerate soft tissue maturation in esthetic periodontal surgery. Compend Contin Educ Dent. 2001 Sep;22(9):72932.

25. Pfeilschifter J, Oechsner M, Naumann A, Gronwald RG, Minne HW, Ziegler R. Stimulation of bone matrix apposition in vitro by local growth factors: a comparison between insulin-like growth factor I, platelet-derived growth factor, and transforming growth factor beta. Endocrinology. $1990 \mathrm{Jul} ; 127(1): 69-75$.

26. Pierce GF, Mustoe TA, Altrock BW, Deuel TF, Thomason A. Role of plateletderived growth factor in wound healing. J Cell Biochem. 1991 Apr;45(4):31926.

27. Pierce GF, Tarpley JE, Yanagihara D, Mustoe TA, Fox GM, Thomason A. Platelet-derived growth factor (BB homodimer), transforming growth factor-beta 1, and basic fibroblast growth factor in dermal wound healing. Neovessel and matrix formation and cessation of repair. Am J Pathol. 1992 Jun;140(6):1375-88.

28. Powell DM, Chang E, Farrior EH. Recovery from deep-plane rhytidectomy following unilateral wound treatment with autologous platelet gel: a pilot study. Arch Facial Plast Surg. 2001 Oct-Dec;3(4):245-50.

29. Rosenberg ES, Torosian J. Sinus grafting using platelet-rich plasma-initial case presentation. Pract Periodontics Aesthet Dent. 2000 Nov-Dec;12(9):843-50.

30. Rutherford RB, Niekrash CE, Kennedy JE, Charette MF. Platelet-derived and insulin-like growth factors stimulate regeneration of periodontal attachment in monkeys. J Periodontal Res. 1992 Jul;27(4 Pt 1):285-90.

31. Shanaman R, Filstein MR, Danesh-Meyer MJ. Localized ridge augmentation using GBR and platelet-rich plasma: case reports. Int J Periodontics Restorative Dent. 2001 Aug;21(4):345-55.

32. Sonnleitner D, Huemer P, Sullivan DY. A simplified technique for producing platelet-rich plasma and platelet concentrate for intraoral bone grafting techniques: a technical note. Int J Oral Maxillofac Implants. 2000 NovDec;15(6):879-82.

33. Vikjaer D, Blom S, Hjørting-Hansen E, Pinholt EM. Effect of platelet-derived growth factor-BB on bone formation in calvarial defects: an experimental study in rabbits. Eur J Oral Sci. 1997 Feb;105(1):59-66.

34. Wang HL, Pappert TD, Castelli WA, Chiego DJ Jr, Shyr Y, Smith BA. The effect of platelet-derived growth factor on the cellular response of the periodontium: an autoradiographic study on dogs. J Periodontol. 1994 May;65(5):429-36.

35. Weibrich G, Hansen T, Kleis W, Buch R, Hitzler WE. Effect of platelet concentration in platelet-rich plasma on peri-implant bone regeneration. Bone. 2004 Apr;34(4):665-71.

36. Whitman DH, Berry RL, Green DM. Platelet gel: an autologous alternative to fibrin glue with applications in oral and maxillofacial surgery. J Oral Maxillofac Surg. 1997 Nov;55(11):1294-9.

37. Whitman DH, Berry RL. A technique for improving the handling of particulate cancellous bone and marrow grafts using platelet gel. J Oral Maxillofac Surg. 1998 Oct;56(10):1217-8.

38. Wikesjö UM, Guglielmoni P, Promsudthi A, Cho KS, Trombelli L, Selvig KA, Jin L, Wozney JM. Periodontal repair in dogs: effect of rhBMP-2 concentration on regeneration of alveolar bone and periodontal attachment. J Clin Periodontol. 1999 Jun;26(6):392-400.

Fonte de financiamento: não há Conflito de interesse: não há Recebido para publicação: 10/06/2008 Aceito para publicação: 25/09/2008 